WEIMIN MA, Ph.D. ${ }^{1}$

E-mail: mawm@tongji.edu.cn

NANNAN LIN, Ph.D. ${ }^{1}$

(Corresponding author)

E-mail: yiyi880922@163.com

XIAOXUAN CHEN, Ph.D. ${ }^{2}$

E-mail: 504836931@qq.com

WENFEN ZHANG, Ph.D. ${ }^{3}$

E-mail: 1076380047@qq.com

${ }^{1}$ School of Economics and Management, Tongji University

No. 1239 Siping Road, Shanghai, China

2 Transmart Technology Inc.

411 S Wells St, Chicago, IL 60607, USA

${ }^{3}$ School of Transportation, Wuhan University of Technology

1048 Heping Avenue, WuChang District, Wuhan, China
Transport Engineering

Original Scientific Paper

Submitted: 15 June 2017

Accepted: 10 July 2018

\title{
A ROBUST OPTIMIZATION APPROACH TO PUBLIC TRANSIT MOBILE REAL-TIME INFORMATION
}

\begin{abstract}
In the past few years, numerous mobile applications have made it possible for public transit passengers to find routes and learn about the expected arrival times of their transit vehicles. Previous studies show that provision of accurate real-time bus information is vital to passengers for reducing their anxieties and wait times at bus stops. Inadequate and/or inaccurate real-time information not only confuses passengers but also reinforces the bad image of public transit. However, almost all methods of real-time information optimization are aimed at predicting bus arrival or travel times. In order to make up for the lack of information accuracy, this paper proposes a new approach to optimize mobile real-time information for each transit route based on robust linear optimization. An error estimation is added to current bus arrival time information as a new element of mobile bus applications. The proof process of the robust optimization model is also presented in this paper. In the end, the model is tested on two comparable bus routes in Shanghai. The real-time information for these two routes was obtained from Shanghai Bus, a mobile application used in Shanghai City. The test results reflect the validity, disadvantages, and risk costs of the model.
\end{abstract}

\section{KEY WORDS}

public transit; mobile app; real-time information; robust optimization;

\section{INTRODUCTION}

The development of intelligent public transport systems and intelligent terminal applications, such as those for mobile phones, tablet PCs, and electronic stop boards, has already significantly improved the level of transit service and satisfaction of transit users. Katrin Dziekan and Karl Kottenhoff [1] concluded that dynamic real-time information had seven main effects on customers: (1) reduced wait time, (2) positive psychological factors, (3) increased willingness-to-pay, (4) adjusted travel behavior, such as better use of wait time or more efficient travel, (5) mode choice effects, (6) higher customer satisfaction, and (7) better image. The research by Kari Edison Watkins and Brian Ferris et al. [2] also showed that mobile real-time information reduced not only the perceived wait time but also the actual wait time experienced by customers. With this development, all kinds of mobile applications providing real-time bus information for customers emerged in response to the needs.

The practical information system used in Shanghai is named Shanghai Bus, developed by the Shanghai Municipal Transport Commission. This application supports both Android and iOS operating systems. It is a query system containing information on bus lines, transfers, circumjacent buses, current location, and a subway map, as shown in Figure 1. Customers can position themselves by "my location", "choose on map", and "road fuzzy query", and obtain bus information such as timetables, stops, and transfers. By the end of 2015 , this system managed real-time information of more than 530 bus lines, including plate numbers, stops counts, and the predicted arrival time of the nearest three buses to the waiting stop. Shanghai Bus does this by using the underlying data feed from the Automatic Vehicle Location (AVL) system and prediction algorithms. Figure 1 shows the iOS interface of the Shanghai Bus application in the Chinese version.

In addition, Jan-Willem Grotenhui and Bart W. Wiegmans et al. [3] did a study to identify customers' desired quality of travel information provision in public transport. Their research showed that passengers had many requirements for real-time information. The real-time information needs could be assigned to 


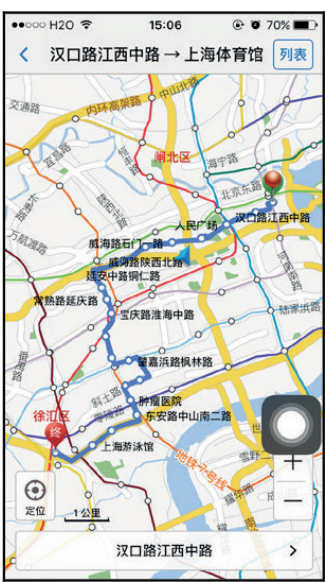

a) Bus line query

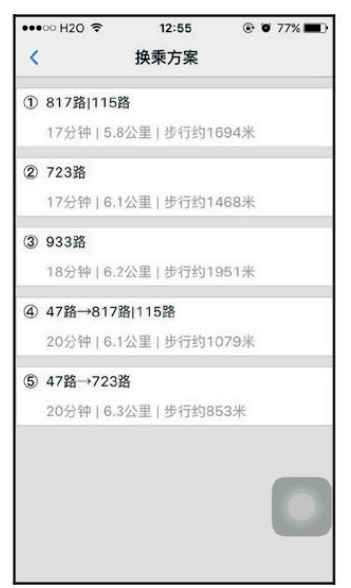

b) Transfer query

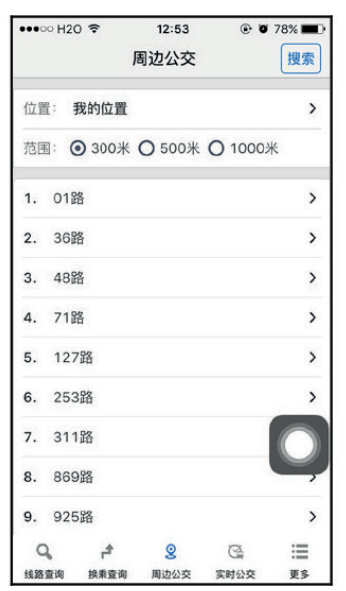

c) Circumjacent buses

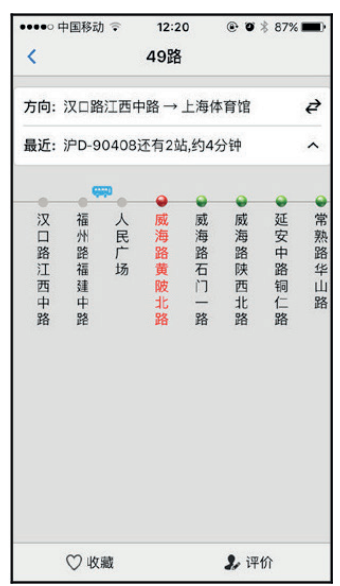

d) Current location

Figure 1 - Interfaces of Shanghai Bus

three distinct stages of a trip, roughly in common with three location types: pre-trip, wayside, and on board. In all stages, total travel time and delay were the most sought-after information; wait time, route, distance, etc., were close behind. Apparently, time information was the most important to customers, e.g. total travel time, delay, or arrival time error, which are the factors Shanghai Bus currently lacks. However, the vast population and heavy traffic in Shanghai makes it harder to realize all trips on time.

Hence, the purpose of this paper is to offer an approach to optimize the real-time arrival information for each transit route by means of adding error estimation to the current arrival times in Shanghai Bus, to account for the uncertainty of public demand. The method proposed in this paper is applicable to a wide range of intelligent public transport systems, combining computational tractability with the structural properties of the optimal policy.

The paper is structured as follows. In Section 2, existing research on real-time bus information is summarized. In Section 3, a robust optimization approach is applied to establish the optimization model. The solving algorithm is introduced in Section 4, and the method is implemented in Section 5. Finally, Section 6 provides some concluding remarks.

\section{LITERATURE REVIEW}

Public transport systems are increasingly equipped with information and communication technologies to improve level of service to passengers and facilitate fleet management [4] (Casey et al., 2000). The dissemination of accurate and reliable information to passengers is of great importance for public transport agencies. ATIS and Advanced Data Collection techniques, such as Automatic Vehicle Location and Automatic Passenger Counts, had first been used to improve operations and management. Later, they were also utilized to disseminate real-time information to passengers $[5,6]$. With the development of such systems, public transport agencies obtain details regarding fleet positioning, travel times and speed, passengers on board, and dwell times at stops. Those sources are then processed and integrated to generate real-time information concerning the present and future states of the public transport system. Real-time information can refer to information on service disruptions, crowding conditions, and prescriptive journey planners. However, the most commonly provided and the focus of research is the information concerning the remaining wait time, since it constitutes an important and uncertain part of the trip. Accurate bus arrival time information is very important to passengers because it reduces wait times and anxiety at bus stations.

Previous studies about real-time bus arrival information mainly focused on two aspects. One is the approaches to real-time bus arrival time prediction, which could be mainly divided into the following categories: artificial neural network (ANN) [6-10], Kalman filtering [11-13], support vector machines (SVM) [1418], regression analysis models [19], and time series models [20]. These five methods were the most commonly used approaches for arrival time prediction. In addition, there were other methods: k-NN classifier [21], glowworm swarm optimization (GSO) [22], multiple data sources [23], meta-model approach [24], real-time data [25-27], and hybrid method [28-30]. Among these methods, some required special conditions and more processing time. Some fully depended on researchers' experience or knowledge to preprocess data to select control parameters. In addition the accuracy of prediction also needed to be improved.

The other research point was the impact of real-time information provision on various aspects of passengers' experience, including the level of satisfaction [33] and perceived wait time [1, 32]. Watkins et al. [2] delved into the importance of providing accurate information and its implications on passengers' 
perception of wait time. In their study, passengers perceived the wait time as 0.83 minutes longer than the actual wait time they had experienced. In contrast, this overestimation of wait time did not occur when real-time information was available. Moreover, the average actual wait time of the latter group was 30\% shorter than the wait time experienced by passengers who used traditional arrival time information (i.e., timetables). The benefits of real-time information were not limited to a single trip stage. Labell et al. [33] reported the advantages of real-time information in improving transfer and departure time decisions based on pre-trip information (e.g., initial connections); improving time usage in/near the terminal; and informing passengers about irregularities in public transport services, and hence reducing passengers' anxiety associated with travel time uncertainty. Moreover, the benefits from deploying real-time information systems are not limited to uncertainty reduction and trip departure time choice. Real-time information can also facilitate path choice changes that yield time savings [34, 35].

Even though considerable research efforts have been devoted to the development of real-time bus arrival prediction schemes and to identifying the impacts of real-time bus information on passengers, there is a lack of consideration for the complexity of real-life conditions. In practice, there will be some inaccuracies of information caused by uncertainties, such as signal problems and huge volumes, no matter how accurate the model or algorithm is. Hence, this paper offers a new approach to optimizing information content by adding error prediction to current real-time arrival information to reduce the negative impacts on passengers caused by inaccurate information.

\section{MODEL BUILDING}

\subsection{Basic model}

Table 1 shows the symbols, which have the same meanings throughout the paper.

Assumptions:

1) The evaluated transit route was equipped with an Automatic Vehicle Location (AVL) system and electronic information boards system.

2) There was only one choice for the passengers, without consideration of other lines' competition.

3) The average speed of passenger boarding on the bus was known and fixed.

4) All the passengers had been waiting at the stop before the bus arrived.

5) The bus's cycle of run and departure intervals were known. The departure interval was fixed and the bus was punctual at the first stop.
6) The travel time distribution was known. In practice, this distribution could be obtained from historical AVL data and parameter calibration.

7) All the researched buses had the same type and capacity. The bus capacity was known.

Consider a normal intelligent bus line, as shown in Figure 2. Here, $n(n \geqslant 3)$ is the number of stops for this line. $j$ are the stop passengers waiting for buses. The yellow box is the nearest bus to stop $j$, which had just left stop $i . k$ is the number of stops between stop $j$ and stop $i$.

The following diagrams present the relationship between passenger numbers and time, including passenger accumulation and dissemination, bus arrival and departure. Figure 3 shows the relationship between passenger numbers and time at stop $j$ without intelligent information, where $\lambda_{0 j}$ is the arrival rate, $t$ is time, $Q$ is the number of passengers at stop $j$ at moment $t$, but not the passengers who have already boarded the vehicle. $Q$ and $t$ have the same meanings in the following figures.

If passengers can get the bus information, including the location, predicted wait time and prediction-error time, from the electronic information board or the mobile terminal, some of them will do something else instead of tiresome waiting. Then the relationship changes to Figure 4, where $\Delta \hat{t}_{j}$ is the prediction-error time. Apparently, passengers' waiting cost at stop $j$ decreases.

According to bus delay communication theory, if the bus arrives at stop $i$ with a delay $\Delta t_{i}$, then there will be a greater delay $\Delta t_{i}^{\prime}$, as shown in Figure 5 where:

$\left\{\begin{array}{l}t_{1}=\frac{Q_{1}}{\lambda_{1 i}} \\ t_{2}-t_{1}=\frac{Q_{2}-Q_{1}}{\lambda_{2 i}} \\ t_{3}-t_{1}=\frac{Q_{3}-Q_{1}}{\lambda_{2 i}} \\ t_{4}-t_{2}=\frac{Q_{2}}{\mu} \\ t_{5}-t_{3}=\frac{Q_{3}}{\mu}\end{array}\right.$

Thus:

$\Delta t_{i}^{\prime}=t_{5}-t_{4}=\left(1+\frac{\lambda_{2 i}}{\mu}\right) \Delta t_{i}$

Besides, if the bus is late, the bus driver will take some steps, such as adjusting the speed to reduce the delay as much as possible. Because of this recovery behavior, the delay to the next stop $i+1$ reduces to $\alpha \Delta t_{i}^{\prime}$, where $\alpha$ is driver's recovery coefficient of delay. This is expressed as

$\Delta t_{i+1}=\alpha t_{i}^{\prime}=\alpha\left(1+\frac{\lambda_{2 i}}{\mu}\right) \Delta t_{i}$

and so on; the delay in arriving at stop $j$ is as shown.

$\Delta t_{j}=\Delta t_{i+k}=\alpha^{k}\left[\prod_{s=i}^{j}\left(1+\frac{\lambda_{2 s}}{\mu}\right)\right] \Delta t_{i}$ 
Table 1 - Symbols used in this paper

\begin{tabular}{|c|l||}
\hline \hline Sympols & \\
\hline$T_{i j}$ & Prediction travel time from stop $i$ to stop $j ;$ \\
\hline$\Delta t_{i}, \Delta t_{j}$ & The actual delay arriving to stop $i$ and stop $j ;$ \\
\hline$\Delta t_{i}, \Delta t_{j}^{\prime}$ & The actual delay leaving stop $i$ and stop $j ;$ \\
\hline$\Delta \hat{t}_{i}, \Delta \hat{t}_{j}$ & The prediction-error time arriving to stop $i$ and stop $j ;$ \\
\hline$\mu$ & Average speed of passenger getting on the bus; \\
\hline$\lambda_{0 i}, \lambda_{0 j}$ & Passenger arrival rate at bus stop $i$ and stop $j$ without intelligent information; \\
\hline$\lambda_{1 i}, \lambda_{1 j}$ & Passenger arrival rate out of prediction-error time at bus stop $i$ and stop $j$ with intelligent information; \\
\hline$\lambda_{2 i}, \lambda_{2 j}$ & Passenger arrival rate within prediction-error time at bus stop $i$ and stop $j$ with intelligent information; \\
\hline$C_{j}$ & Passengers' time cost saving at bus stop $j$ with intelligent information; \\
\hline$c_{0}$ & Passenger waiting cost coefficient without intelligent information; \\
\hline$c_{1}$ & Passenger waiting cost coefficient out of prediction-error time with intelligent information; \\
\hline$c_{2}$ & Passenger waiting cost coefficient within prediction-error time with intelligent information; \\
\hline$\alpha$ & Driver's recovery coefficient of delay; \\
\hline$N$ & Number of buses deployed on the transit route; \\
\hline$h$ & Headway of the transit route; \\
\hline$U$ & Bus capacity \\
\hline$Q_{i}, Q_{j}$ & Total number of passengers waiting at stop $i$ and stop $j ;$ \\
\hline$P_{i}, P_{j}$ & The number of passengers geting off at stop $i$ and stop $j ;$ \\
\hline$T$ & One-way travel time of the transit route, including the time from the starting point to the terminal point \\
\hline
\end{tabular}

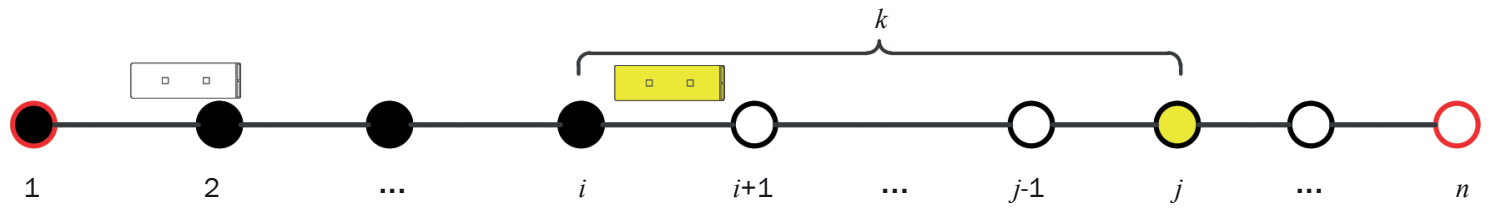

Figure 2 - Diagram of an intelligent bus line

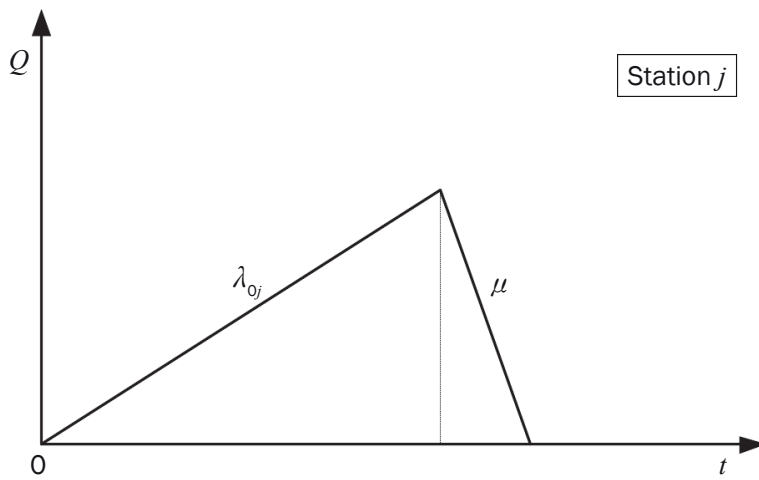

Figure 3 - Diagram without intelligent information

Figure 6 shows the relationship between passenger numbers and time stop $j$ with both intelligent information and delay.

Let $C_{j}(\$)$ be passengers' time cost saving at stop $j$ with intelligent information, $c_{0}(\$ /$ person $)$ passenger waiting cost coefficient without intelligent information, $c_{1}(\$ /$ person) passenger waiting cost coefficient in time period $\left(0, t_{1}\right)$ with intelligent information, and

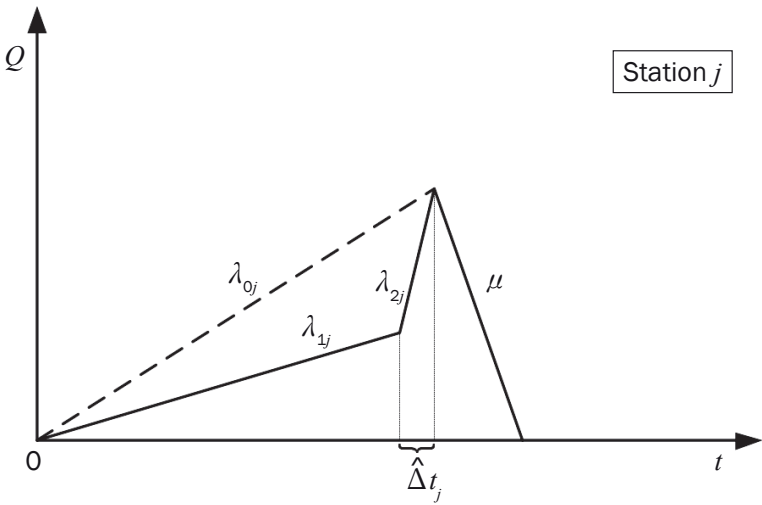

Figure 4 - Diagram with intelligent information

$c_{2}(\$ /$ person) passenger waiting cost coefficient in time period $\left(t_{1}, t_{3}\right)$ with intelligent information. The objective function is passengers' time cost saving at a stop caused by intelligent information, and it is expressed by passengers' total time cost in case of no intelligent information $\left(c_{0} \lambda_{0 j} t_{1}\right)$ minus passengers' total time cost in case of provision of intelligent information, 


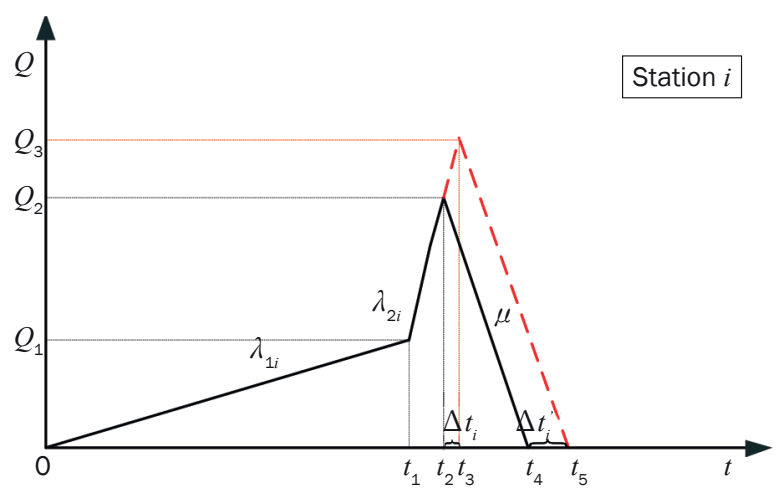

Figure 5 - Diagram 1 with intelligent information and delay

which includes passengers' time cost not using intelligent information $\left(c_{1} \lambda_{1 j} t_{1}\right)$ and passengers' time cost using intelligent information $\left(c_{2} \lambda_{2 j}\left(t_{3}-t_{1}\right)\right)$. Then the expression of $C_{j}$ is as below:

$$
\begin{aligned}
C_{j}= & c_{0} \lambda_{0 j} t_{3}-\left[c_{1} \lambda_{1 j} t_{1}+c_{2} \lambda_{2 j}\left(t_{3}-t_{1}\right)\right] \\
= & c_{0} \lambda_{0 j}\left(t_{2}+\Delta t_{j}\right)-\left[c_{1} \lambda_{1 j}\left(t_{2}-\Delta \hat{t}_{j}\right)+\right. \\
& \left.+c_{2} \lambda_{2 j}\left(\Delta t_{j}+\Delta \hat{t}_{j}\right)\right]
\end{aligned}
$$

where $t_{2}$ is the departure interval, and $t_{2}=h$. Then,

$$
C_{j}=c_{0} \lambda_{0 j}\left(h+\Delta t_{j}\right)-\left[c_{1} \lambda_{1 j}\left(h-\Delta \hat{t}_{j}\right)+c_{2} \lambda_{2 j}\left(\Delta t_{j}+\Delta \hat{t}_{j}\right)\right]
$$

As can be seen from Figure 4 , the value of $C_{j}$ chang es with $\Delta \hat{t}_{j}$.

Furthermore, it is highly possible that there are so many passengers waiting at the bus stops that one bus cannot take them all during peak times. Those passengers left behind have to wait for the next bus. Their waiting cost increases by $h$. And the total time cost saving $C_{j}$ decreases by $c_{0}\left(Q_{0} \cdot h\right) \cdot Q_{0}$ is the number of left-behind passengers, and $Q_{0}=\sum_{k=1}^{j}\left(Q_{k}-P_{k}\right)-U$. $Q_{k}$ is the total number of passengers waiting at stop $k$; $P_{k}$ is the total number of passengers getting off at stop $k ; U$ is the bus capacity. Thus,

$$
\begin{aligned}
C_{j} & =c_{0} \lambda_{0 j}\left(h+\Delta t_{j}\right)-\left[c_{1} \lambda_{1 j}\left(h-\Delta \hat{t}_{j}\right)+\right. \\
& \left.+c_{2} \lambda_{2 j}\left(\Delta t_{j}+\Delta \hat{t}_{j}\right)\right]-c_{0}\left[\sum_{k=1}^{j}\left(Q_{k}-P_{k}\right)-U\right] h
\end{aligned}
$$

Aiming to maximize the total time cost saving of all stops in the transit route, the following model has been established.

$$
\begin{array}{ll}
\text { maximize } & \sum_{j=2}^{n} C_{j} \\
\text { subject to } & \sum_{j=2}^{n} \Delta \hat{t}_{j} \leqslant \frac{h N}{2}-T
\end{array}
$$

In Problem LP1, $h$ and $\Delta t_{j}(\alpha, \lambda)$ are known, $c$ and $\lambda$ are random variables, and $\Delta \hat{t}_{j}$ is the decision variable. $N$ is the number of buses on the selected transit route, $h$ is the headway of the selected transit route, $T$ is the one-way travel time of the selected transit route, including the time from the starting point to the terminal point and the rest time in the end. The first

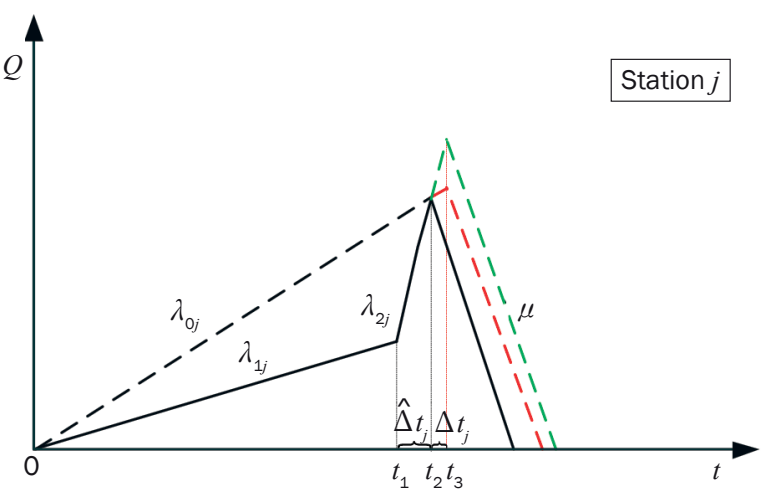

Figure 6 - Diagram 2 with intelligent information and delay

constraint means the total error is not higher than the value determined by the number of operating vehicles, departure interval, and the one-way travel time.

\subsection{Robust optimization model}

We used the objective maximize $z$, and added the constraint $z-\sum C_{j} \leqslant 0$, to make the data uncertainty only affect the elements in the constraint. Then the Problem LP1 equals Problem LP2.

maximize $z$

$$
\begin{array}{ll}
\text { subject to } & z-\sum_{j=2}^{n} C_{j} \leqslant 0 \\
& \sum_{j=2}^{n} \Delta \hat{t}_{j} \leqslant \frac{h N}{2}-T
\end{array}
$$

In Problem LP2, the first constraint can be written as:

$$
\begin{aligned}
z & -\sum_{j} C_{j} \\
= & z-\sum_{j}\left\{c_{0} \lambda_{0 j}\left(h+\Delta t_{j}\right)-\left[c_{1} \lambda_{1 j}\left(h+\Delta \hat{t}_{j}\right)+\right.\right. \\
& \left.\left.+c_{2} \lambda_{2 j}\left(\Delta t_{j}+\Delta \hat{t}_{j}\right)\right]-c_{0}\left[\sum_{k=1}^{j}\left(Q_{k}-P_{k}\right)-U\right] h\right\} \\
= & z-\sum_{j}\left\{c_{0} \lambda_{0 j}\left(h+\Delta t_{j}\right)-c_{1} \lambda_{1 j} h-c_{2} \lambda_{2 j} \Delta t_{j}+c_{1} \lambda_{1 j} \Delta \hat{t}_{j}-\right. \\
& \left.-c_{2} \lambda_{2 j} \Delta \hat{t}_{j}-c_{0}\left[\sum_{k=1}^{j}\left(Q_{k}-P_{k}\right)-U\right] h\right\} \\
= & z-\sum_{j}\left\{c_{0} \lambda_{0 j}\left(h+\Delta t_{j}\right)-c_{1} \lambda_{1 j} h-c_{2} \lambda_{2 j} \Delta t_{j}-\right. \\
& \left.-c_{0}\left[\sum_{k=1}^{j}\left(Q_{k}-P_{k}\right)-U\right] h\right\}+\sum_{j}\left(c_{2} \lambda_{2 j}-c_{1} \lambda_{1 j}\right) \Delta \hat{t}_{j} \leqslant 0
\end{aligned}
$$

That is,

$\sum_{j}\left(c_{2} \lambda_{2 j}-c_{1} \lambda_{1 j}\right) \Delta \hat{t}_{j} \leqslant \sum_{j}\left\{c_{0} \lambda_{0 j}\left(h+\Delta t_{j}\right)-c_{1} \lambda_{1 j} h-\right.$

$\left.-c_{2} \lambda_{2 j} \Delta t_{j}-c_{0}\left[\sum_{k=1}^{j}\left(Q_{k}-P_{k}\right)-U\right] h\right\}-z$

In Formula 9, let $a_{j}=\mathrm{c}_{2} \lambda_{2 j}-\mathrm{c}_{1} \lambda_{1 j}$, and $b=\sum_{j}\left\{c_{0} \lambda_{0 j}\right.$ $\left.\left(h+\Delta t_{j}\right)-c_{1} \lambda_{1 j} h-c_{2} \lambda_{2 j} \Delta t_{j}-c_{0}\left[\sum_{k=1}^{j}\left(Q_{k}-P_{k}\right)-U\right] h\right\}-z$ for clearer expressions. Let $\mathbf{A}$ represent the set of coefficients that are subject to uncertainty. Each entry 
$a_{j}, a_{j} \in \mathbf{A}$ takes values according to a symmetric distribution with a mean equal to the nominal value $a_{j}$ in the interval $\left[a_{j}-\hat{a}_{j}, a_{j}+\hat{a}_{j}\right]$. Then the Problem LP2 can be simplified:

maximize $z$

$$
\begin{aligned}
\text { subject to } & \sum_{j=2}^{n} a_{j} \Delta \hat{t}_{j} \leqslant b \\
& \sum_{j=2}^{n} \Delta \hat{t}_{j} \leqslant \frac{h N}{2}-T
\end{aligned}
$$

We introduced an integer parameter $\Gamma$, that takes values in the interval $[0,|\mathbf{A}|]$. As becomes clear below, the role of the parameter $\Gamma$ is to adjust the robustness of the proposed method against the level of conservatism of the solution [36]. Speaking intuitively, it is unlikely that all of the $a_{j}$ would change.

Consider the following (still nonlinear) Problem LP4 [37].

$$
\begin{aligned}
\text { maximize } & z \\
\text { subject to } & \sum_{j=2}^{n} a_{j} \Delta \hat{t}_{j} \max \{S|S \subseteq A,| S \mid=\Gamma\} \\
& \left\{\sum_{j \in S} \hat{a}_{j}\left|\Delta \hat{t}_{j}\right| t_{j}\right\} \leqslant b-t_{j} \leqslant \Delta \hat{t}_{j} \leqslant \Delta t_{j} \\
& \sum_{j=2}^{n} \Delta \hat{t}_{j} \leqslant \frac{h N}{2}-T
\end{aligned}
$$

In Problem LP4, the first constraint is protected by $\beta(\Delta \hat{\mathbf{t}}, \Gamma), \beta(\Delta \hat{\mathbf{t}}, \Gamma)=$ $=\max \{\mathbf{S}|\mathbf{S} \subseteq \mathbf{A},| \mathbf{S} \mid=\Gamma\}\left\{\sum_{j \in \mathbf{S}} \hat{a}_{j}\left|\Delta \hat{t}_{j}\right|\right\}$. Note that when $\Gamma=0, \beta(\Delta \hat{\mathbf{t}}, \Gamma)=0$, the constraints are equivalent to that of the nominal problem. Therefore, by varying $\Gamma \in[0,|\mathbf{A}|]$, we have the flexibility of adjusting the robustness of the method against the level of conservatism of the solution.

To reformulate Problem LP4 as a linear optimization model, given vector $\Delta \hat{\mathbf{t}}^{*}$, the protection function of the first constraint is

$$
\beta\left(\Delta \hat{\mathbf{t}}^{*}, \Gamma\right)=\max \{\mathbf{S}|\mathbf{S} \subseteq \mathbf{A},| \mathbf{S} \mid=\Gamma\}\left\{\sum_{j \in \mathbf{S}} \hat{a}_{j}\left|\Delta \hat{t}_{j}^{*}\right|\right\}
$$

It equals the objective function of the following linear optimization problem LP5:

$$
\begin{array}{cl}
\text { maximize } & \sum_{j=2}^{n} \hat{a}_{j}\left|\Delta \hat{t}_{J}^{*}\right| q_{j} \\
\text { subject to } & \sum_{j=2}^{n} q_{j} \leqslant \Gamma \\
0 \leqslant q_{j} \leqslant 1
\end{array}
$$

This was equivalent to the selection of the subset $\{\mathbf{S}|\mathbf{S} \subseteq \mathbf{A},| \mathbf{S} \mid=\Gamma\}$ with the corresponding cost function $\left\{\sum_{j \in \mathbf{S}} \hat{a}_{j}\left|\Delta \hat{t}_{j}\right|\right\}$.

Consider the dual of Problem LP5:

$$
\begin{array}{ll}
\text { maximize } & \sum_{j=2}^{n} r_{j}+\Gamma q \\
\text { subject to } & q+r_{j} \geqslant \hat{a}_{j}\left|\Delta \hat{t}_{j}^{*}\right| \\
& r_{j} \geqslant 0 \\
& q \geqslant 0
\end{array}
$$

Here, $q$ and $r$ are variables generated through the evolution of models. By strong duality, since Problem LP5 is feasible and bounded for all $\Gamma \in[0,|\mathbf{A}|]$, the dual Problem LP6 is also feasible and bounded, and their objective values coincide. Using the change from Formula 10 to Problem LP5, we have that $\beta\left(\Delta \hat{\mathbf{t}}^{*}, \Gamma\right)$ is equal to the objective function value of Problem LP6. Also, at optimality, clearly, $t_{j}=\left|\Delta \hat{t}_{j}^{*}\right|$. Substituting to Problem LP4, the Problem LP4 is equivalent to the linear optimization problem $L P 7$.

$$
\begin{array}{cl}
\text { maximize } & z \\
\text { subject to } & \sum_{j=2}^{n} a_{j} \Delta \hat{t}_{j}+\sum_{j=2}^{n} r_{j}+\Gamma q \leqslant b \\
& q+r_{j} \geqslant \hat{a}_{j} t_{j} \\
& -t_{j} \leqslant \Delta \hat{t}_{j} \leqslant t_{j} \\
& \sum_{j=2}^{n} \Delta \hat{t}_{j} \leqslant \frac{h N}{2}-T \\
& r_{j} \geqslant 0 \\
& q \geqslant 0 \\
& t_{j} \geqslant 0
\end{array}
$$

Replacing $a_{j}$ and $b$ by the primary expressions results in the final robust optimization model $L P 8$.

$$
\begin{aligned}
& \text { maximize } z \\
& \text { subject to } \\
& z \leqslant \sum_{j=2}^{n}\left\{c_{0} \lambda_{0 j}\left(h+\Delta t_{j}\right)-\left[c_{1} \lambda_{1 j}\left(h-\Delta \hat{t}_{j}\right)+\right.\right. \\
& \left.\left.+c_{2} \lambda_{2 j}\left(\Delta t_{j}+\Delta \hat{t}_{j}\right)\right]-c_{0}\left[\sum_{k=1}^{j}\left(Q_{k}-P_{k}-U\right)\right] h\right\}- \\
& -\left(q \Gamma+\sum_{j=2}^{n} r_{j}\right) \\
& q+r_{j} \geqslant \hat{a}_{j} t_{j} \\
& -t_{j} \leqslant \Delta \hat{t}_{j} \leqslant t_{j} \\
& \sum_{j=2}^{n} \Delta \hat{t}_{j} \leqslant \frac{h N}{2}-T \\
& r_{j} \geqslant 0 \\
& q \geqslant 0 \\
& t_{j} \geqslant 0
\end{aligned}
$$

\section{SOLVING ALGORITHM}

The robust optimization problem is characterized by huge computation, so a high-performance algorithm is needed. The predatory search algorithm, PSA, is a new kind of bionic algorithm. This algorithm defines local and global search by the restriction value of search space and realizes the conversion between 
local and global search by adjusting the restriction value of search space. It has better ability to conduct local search and jump out of local optimal solution simultaneously. This was the algorithm used in this paper to search for the optimal robust solution. If the robust optimization function is a maximize problem, turn it to be a minimize problem.

There are two parts of PSA.

1) Global search: search in the whole space, and if the prey or sign is found, turn to 2 ).

2) Local search: search closely in the neighborhood of the prey, and if there is no progress for a long time, turn to 1$)$.

This paper uses the method of restricting target value, proposed by Linhares [38]. This method has a set of target values according to the search in the neighborhood of the current optimal solution, where the smaller ones are set as local search restrictions and the larger ones as global search restrictions.

\section{NUMERICAL IMPLEMENTATION}

In this section, an experiment illustrating the robust solution to real-time transit timetable problem is presented. According to a survey of all the intelligent transit routes in Shanghai and their indexes of crowdedness, congestion, noise, wait time, and service, No. 49 (a city bus line) and Beian Line (a suburban bus line) were taken as the numerical examples to assess the proposed robust optimization model. No. 49 had 20 bus stops, and Beian Line had 36, including the starting and ending terminals. In this paper, passenger flow, especially high volumes or unusual events, is considered as the uncertain value in model building. High passenger flow happens much more often in evenings due to rush hours and students traveling from school in some stops. Hence, for a more evident result comparison, the evening peak period (17:0019:00) has been considered in this example. The two bus routes respectively had 30 buses and 20 buses. The maximum passenger capacity was 86 . The data acquisition times were the evening peak hours on 12-16 September 2016. The scheduled headways of the two routes in the evening peak hours were $5 \mathrm{~min}$ and $10 \mathrm{~min}$, separately. Table 2 shows the basic information on No. 49 and Beian Line.
Regarding the driver's recovery coefficient of delay $\alpha$, Chen et al. [39] used the AVL data and timetable from a reputable transit agency in the northeastern United States and obtained the distribution of the recovery coefficient along the route. Their results showed that, on most segments, the average recovery coefficients were mostly between -0.5 and 0.5 . In this paper, the recovery coefficient is assumed to be non-negative, i.e., bus drivers were always trying to recover the schedule deviation. It was thus assumed that the recovery coefficient of delay $\alpha$ was uniformly distributed in the interval $[0,0.5]$. According to Equation 4, the value of $\Delta t_{j}$ was known based on the gathered AVL data. In addition, the average speed of passenger getting on the bus $\mu$ was 10 persons a minute.

The uncertainty variables in this paper are passenger arrival rates $\lambda_{1 j}$ and $\lambda_{2 j}$. The uncertain variable $\lambda_{1 j}$ is modeled as a random variable that has an arbitrary distribution in the interval $\left[0, \bar{\lambda}_{j}\right]$, and the uncertain variable $\lambda_{2 j}$ as a random variable that has an arbitrary distribution in the interval $\left[\bar{\lambda}_{j}, \lambda_{j-\max }\right]$, where $\bar{\lambda}_{j}$ is the average value and $\lambda_{j \text {-max }}$ is the maximum value. The passenger arrival rates $\lambda_{1 j}$ and $\lambda_{2 j}$. are independent.

Three cases for the values of $c_{0}, c_{1}$, and $c_{2}$ are presented. The three cases consider the different mind states of passengers and reflect the popularity of intelligent software like Shanghai Bus. Case 1 assumes all passengers had the same attitude toward the intelligent information, Case 2 assumes the passengers who used the intelligent information have a higher waiting cost coefficient, and Case 3 is much higher than Case 2. Tables 3 and 4 present the ultimate results.

Some key insights are summarized in the example.

1) For the same bus line, different waiting cost coefficients have led to remarkable changes in the results. From Case 1 to Case 3, the prediction-error time $\Delta \hat{t}_{j}$ got smaller and smaller, which implies that the results are more accurate. At the same time, the total time cost saving $\sum C_{j}$ increased, which means the application of the intelligent terminals saved passengers' total waiting cost apparently.

2) There are some negatives in the results of $C_{j}$. This is normal. The negatives reflect the disadvantage of this model, and there is a risk cost. If the bus arrived earlier than the prediction time provided

Table 2 - Basic information of No.49 and Beian Line

\begin{tabular}{|c|c|c|c|c|c|c|c|c|}
\hline \multirow[t]{2}{*}{ Bus name } & \multirow{2}{*}{$\begin{array}{l}\text { Number } \\
\text { of stops }\end{array}$} & \multicolumn{2}{|c|}{$\begin{array}{l}\text { Length } \\
{[\mathrm{km}]}\end{array}$} & \multicolumn{2}{|c|}{$\begin{array}{l}\text { Headway } \\
\text { [min] }\end{array}$} & \multirow{2}{*}{$\begin{array}{l}\text { One-way travel time } \\
{[\text { min] }}\end{array}$} & \multirow{2}{*}{$\begin{array}{l}\text { Number } \\
\text { of buses }\end{array}$} & \multirow{2}{*}{$\begin{array}{c}\text { Bus } \\
\text { capacity }\end{array}$} \\
\hline & & up & down & Peak & Low & & & \\
\hline 49 & 20 & 13.4 & 13.0 & 5-6 & $6-10$ & 60 & 30 & 86 \\
\hline Beian Line & 36 & 16.6 & 17.3 & 10 & 20 & 100 & 20 & 86 \\
\hline
\end{tabular}


by the intelligent terminal, the waiting cost would increase because the passengers missing this bus would have to take the next one.

3) Compared with No. 49, the Beian Line had greater, more unstable errors and greater risk costs. This indicates that the risk cost increased for the bus line providing poorer service. According to the model, these were mainly caused by the differences between the city bus and the suburban bus. No. 49 ran in the center of Shanghai with stable passenger flow, mostly traveling for business purposes. Moreover, although traffic jams always happened, the travel time could be estimated based on histor- ical data. However, the Beian Line started from one central bus stop to another one in a suburb, and stopped at several passenger collector-distributor points, such as a super market, shopping center, material market, coach waiting point, and so on.

4) As shown in Figures $7 a$ and $7 b$, the estimated error of real-time travel time prediction increased while vehicle running time grew and reached the maximum in some stops because of traffic jams or high passenger flows. After that, it was easier for the driver to adjust the driving speed to catch up to the schedule. This shows that driver's recovery behavior plays a key role in the results.

Table 3 - Results of the three cases of No.49 [min]

\begin{tabular}{|c|c|c|c|c|c|c|}
\hline \multirow{2}{*}{$\begin{array}{l}\text { No. } 49 \\
\text { Stop } j\end{array}$} & \multicolumn{2}{|c|}{$\begin{array}{c}\text { Case } 1 \\
c_{0}=c_{1}=c_{2}=1\end{array}$} & \multicolumn{2}{|c|}{$\begin{array}{c}\text { Case } 2 \\
c_{0}=1, c_{1}=0.5, c_{2}=2\end{array}$} & \multicolumn{2}{|c|}{$\begin{array}{l}\text { Case } 3 \\
c_{0}=1, c_{1}=0.3, c_{2}=3\end{array}$} \\
\hline & $\Delta \hat{t}_{j}$ & $C_{j}$ & $\Delta \hat{t}_{j}$ & $C_{j}$ & $\Delta \hat{t}_{j}$ & $C_{j}$ \\
\hline 1 & 0.00 & 0.00 & 0.00 & 0.00 & 0.00 & 0.00 \\
\hline 2 & 0.03 & 0.93 & 0.03 & 0.93 & 0.02 & 0.93 \\
\hline 3 & 0.15 & 0.78 & 0.14 & 0.79 & 0.12 & 0.80 \\
\hline 4 & 0.96 & 5.05 & 0.86 & 5.24 & 0.78 & 5.41 \\
\hline 5 & 1.76 & 7.78 & 1.58 & 8.27 & 1.43 & 8.71 \\
\hline 6 & 1.29 & -0.74 & 1.16 & 0.75 & 1.04 & 1.05 \\
\hline 7 & 1.97 & 2.45 & 1.77 & 2.88 & 1.60 & 3.27 \\
\hline 8 & 2.38 & 2.35 & 2.14 & 2.92 & 1.93 & 3.43 \\
\hline 9 & 1.99 & 2.43 & 1.79 & 2.87 & 1.61 & 3.27 \\
\hline 10 & 2.82 & 2.95 & 2.54 & 3.62 & 2.28 & 4.23 \\
\hline 11 & 2.79 & 2.22 & 2.51 & 2.67 & 2.26 & 3.07 \\
\hline 12 & 3.44 & 0.52 & 3.10 & 1.41 & 2.79 & 2.22 \\
\hline 13 & 1.94 & 1.67 & 1.75 & 1.87 & 1.57 & 2.04 \\
\hline 14 & 2.77 & -2.58 & 2.49 & -0.86 & 2.24 & 0.82 \\
\hline 15 & 1.52 & -0.66 & 1.37 & -0.51 & 1.23 & -0.38 \\
\hline 16 & 1.98 & -0.22 & 1.78 & 0.29 & 1.60 & 0.75 \\
\hline 17 & 1.81 & 3.83 & 1.63 & 4.05 & 1.47 & 4.24 \\
\hline 18 & 1.51 & 0.04 & 1.36 & 1.55 & 1.22 & 0.91 \\
\hline 19 & 0.93 & 0.81 & 0.84 & 0.83 & 0.75 & 0.85 \\
\hline 20 & 0.48 & 0.00 & 0.43 & 0.00 & 0.39 & 0.00 \\
\hline $\begin{array}{l}\text { Total time cost saving } \\
\qquad \sum C_{j}\end{array}$ & - & 29.59 & - & 39.58 & - & 45.63 \\
\hline
\end{tabular}


Table 4 - Results of the three cases of Beian Line [min]

\begin{tabular}{|c|c|c|c|c|c|c|}
\hline \multirow{2}{*}{$\begin{array}{c}\text { Beian Line } \\
\text { Stop } j \\
\end{array}$} & \multicolumn{2}{|c|}{$\begin{array}{c}\text { Case } 1 \\
c_{0}=c_{1}=c_{2}=1\end{array}$} & \multicolumn{2}{|c|}{$\begin{array}{c}\text { Case 2 } \\
c_{0}=1, c_{1}=0.5, c_{2}=2 \\
\end{array}$} & \multicolumn{2}{|c|}{$\begin{array}{c}\text { Case } 3 \\
c_{0}=1, c_{1}=0.3, c_{2}=3\end{array}$} \\
\hline & $\Delta \hat{t}_{j}$ & $C_{j}$ & $\Delta \hat{t}_{j}$ & $C_{j}$ & $\Delta \hat{t}_{j}$ & $C_{j}$ \\
\hline 1 & 0.00 & 0.00 & 0.00 & 0.00 & 0.00 & 0.00 \\
\hline 2 & 0.14 & 0.96 & 0.13 & 0.96 & 0.12 & 0.96 \\
\hline 3 & 0.26 & 0.92 & 0.23 & 0.92 & 0.21 & 0.93 \\
\hline 4 & 0.52 & 0.62 & 0.47 & 0.64 & 0.42 & 0.66 \\
\hline 5 & 1.39 & 1.43 & 1.25 & 1.47 & 1.12 & 1.51 \\
\hline 6 & 1.22 & 2.12 & 1.10 & 2.18 & 0.99 & 2.23 \\
\hline 7 & 2.14 & 5.50 & 1.93 & 5.65 & 1.74 & 5.79 \\
\hline 8 & 2.50 & 0.22 & 2.25 & 0.27 & 2.03 & 0.32 \\
\hline 9 & 2.13 & 3.15 & 1.92 & 3.23 & 1.73 & 3.31 \\
\hline 10 & 2.66 & 0.17 & 2.40 & 0.22 & 2.16 & 0.27 \\
\hline 11 & 3.10 & 4.87 & 2.79 & 5.15 & 2.51 & 5.40 \\
\hline 12 & 3.59 & -0.99 & 3.23 & 0.54 & 2.91 & 0.77 \\
\hline 13 & 3.50 & 4.46 & 3.15 & 4.78 & 2.84 & 5.06 \\
\hline 14 & 4.28 & 4.24 & 3.86 & 4.67 & 3.47 & 5.05 \\
\hline 15 & 4.28 & -1.23 & 3.85 & 0.37 & 3.46 & 0.49 \\
\hline 16 & 4.19 & -0.64 & 3.77 & -0.26 & 3.40 & 0.08 \\
\hline 17 & 4.93 & 3.01 & 4.44 & 3.46 & 3.99 & 3.86 \\
\hline 18 & 5.02 & 0.87 & 4.52 & 1.27 & 4.07 & 1.63 \\
\hline 19 & 5.14 & 1.23 & 4.63 & 1.70 & 4.16 & 2.11 \\
\hline 20 & 5.33 & 1.02 & 4.80 & 1.50 & 4.32 & 1.93 \\
\hline 21 & 5.81 & -0.74 & 5.22 & -0.16 & 4.70 & 0.36 \\
\hline 22 & 5.91 & 0.75 & 5.32 & 1.58 & 4.79 & 2.32 \\
\hline 23 & 6.20 & 0.42 & 5.58 & 1.04 & 5.02 & 1.60 \\
\hline 24 & 6.77 & -3.45 & 6.09 & 0.01 & 5.48 & 0.56 \\
\hline 25 & 7.09 & -2.17 & 6.38 & -1.39 & 5.74 & -0.68 \\
\hline 26 & 7.01 & -1.17 & 6.31 & -0.61 & 5.68 & -0.10 \\
\hline 27 & 6.16 & 0.48 & 5.54 & 1.09 & 4.99 & 1.65 \\
\hline 28 & 5.10 & 1.27 & 4.59 & 1.73 & 4.13 & 2.15 \\
\hline 29 & 4.89 & 1.00 & 4.40 & 1.53 & 3.96 & 2.02 \\
\hline 30 & 4.42 & 0.92 & 3.98 & 1.23 & 3.58 & 1.51 \\
\hline 31 & 4.34 & -0.48 & 3.90 & 0.69 & 3.51 & 0.93 \\
\hline 32 & 4.01 & 0.70 & 3.61 & 0.94 & 3.25 & 1.16 \\
\hline 33 & 3.36 & 0.58 & 3.02 & 0.74 & 2.72 & 0.89 \\
\hline 34 & 3.14 & -0.64 & 2.83 & -0.55 & 2.54 & -0.46 \\
\hline 35 & 2.99 & 0.70 & 2.69 & 0.73 & 2.42 & 0.76 \\
\hline 36 & 2.89 & 0.00 & 2.60 & 0.00 & 2.34 & 0.00 \\
\hline $\begin{array}{l}\text { Total time cost saving } \\
\sum \sum C_{j}\end{array}$ & - & 31.18 & - & 38.71 & - & 42.34 \\
\hline
\end{tabular}




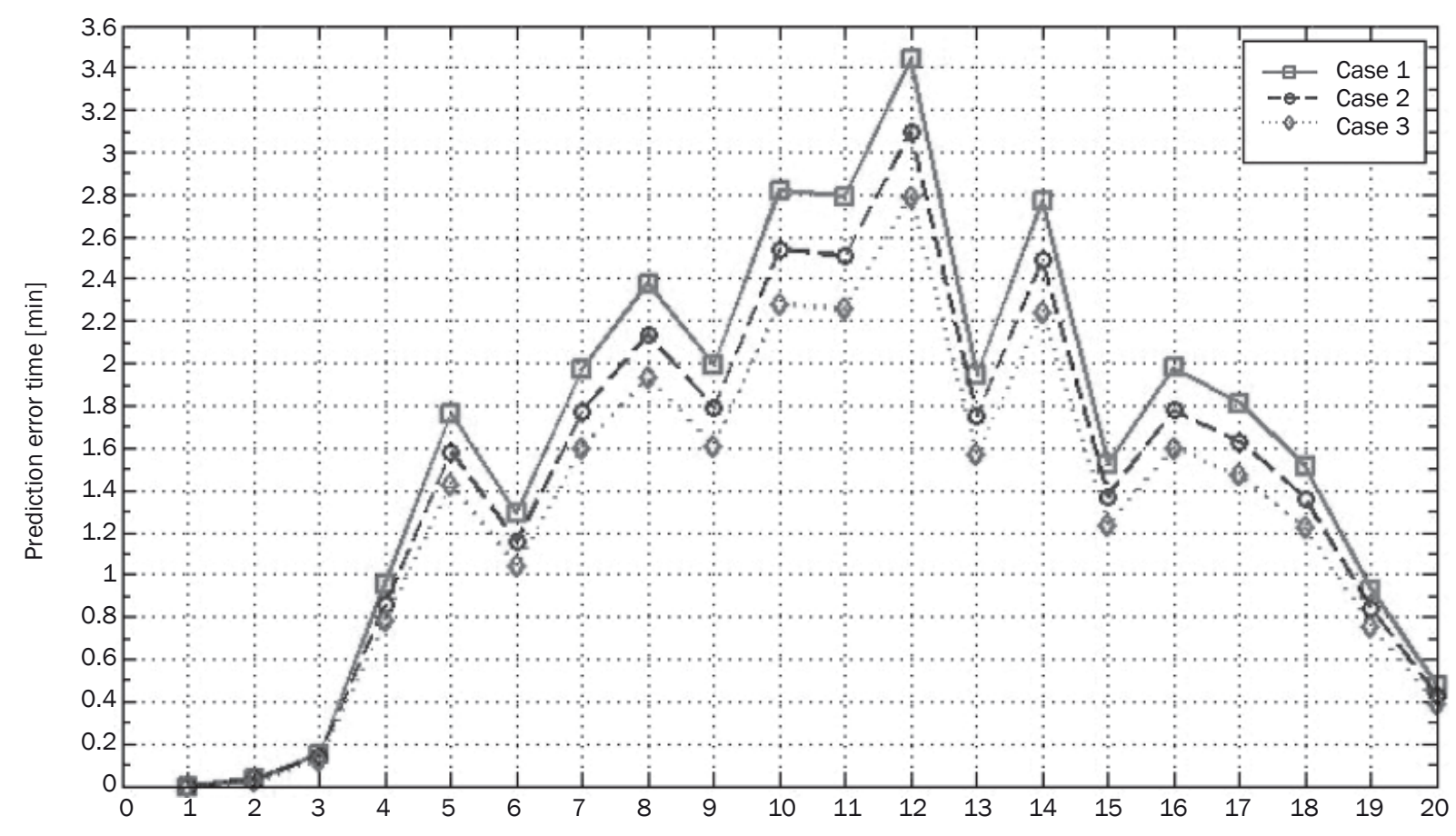

a) No.49

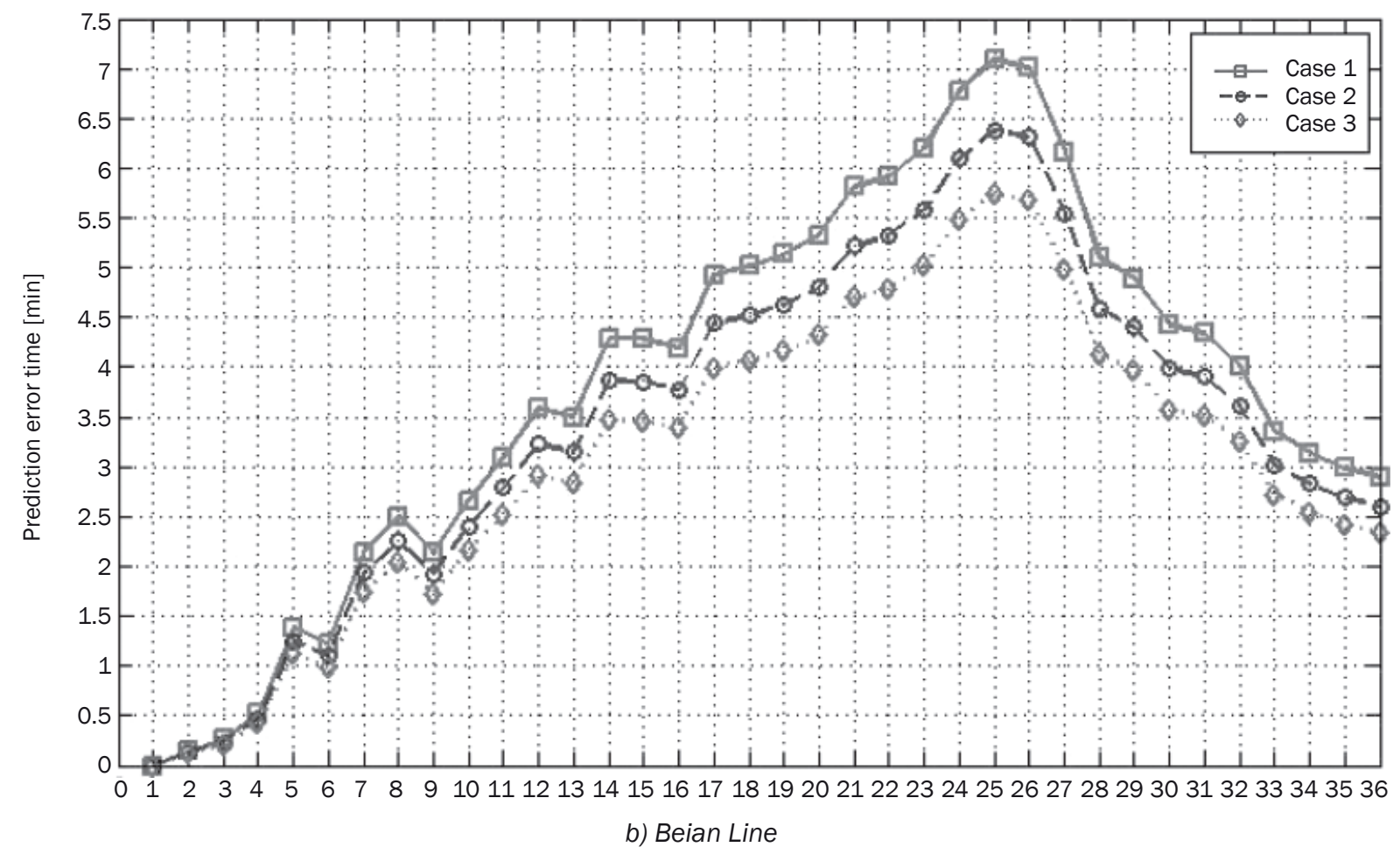

Figure 7 - The values of error prediction $\Delta \hat{t}_{j}$ at the test route stops in the three cases

Besides, the problem for various protection levels of $\Gamma$ was changed from 0 to 20 , taking Case 3 for example. Figure 8 illustrates the performance of the robust solution for various protection levels.

As shown in Figure 8, when $\Gamma=0$, the optimal value is maximized, which is the same with the nominal problem. However, with increasing $\Gamma$, the optimal value decreases on a small scale: the optimal value of No. 49 decreased by $10.69 \%$, and the optimal value of the Beian Line decreased by $7.13 \%$. This suggests that the robust approach has captured the trade-off between unstable passenger flow and passenger waiting cost saving caused by intelligent information. 


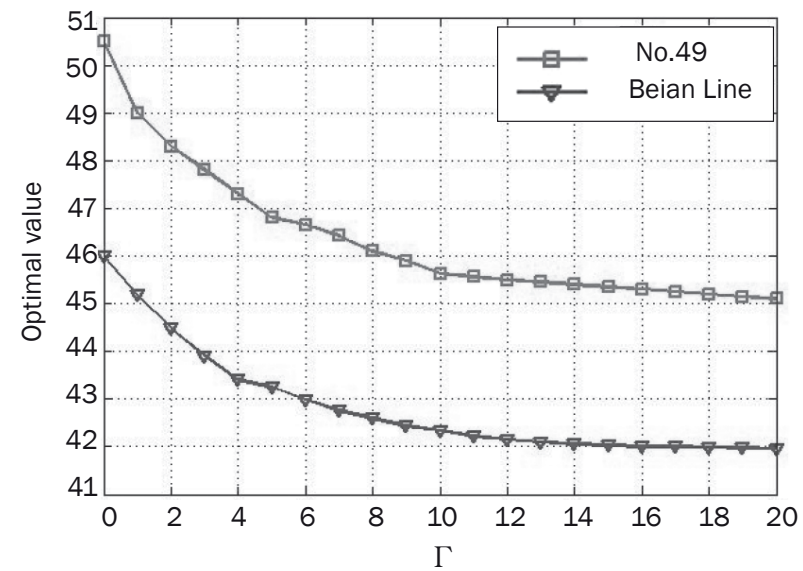

Figure 8 - Optimal value of the robust problem as a function of $\Gamma$

\section{CONCLUSIONS}

In this paper, a robust optimization method is proposed to optimize transit real-time timetable since various intelligent terminals have been put into use. Prediction-error time has been added to current intelligent information, considering the uncertainty of passenger flow and different passenger attitudes to intelligent information. According to the numerical implementation, the model validity has been proven.

This method reduces the cost of passengers' wait time by producing a more accurate timetable, rather than finding a better dispatch policy, which is the biggest difference to the existing approaches. In the existing approaches, the total operation cost or passengers' wait time were considered, but passengers still could not plan optimal trips. According to the approach proposed in this paper, passengers could get real-time bus information to re-plan the whole trip instead of passively waiting at the stops. However, passenger transfer and competition from other bus lines, which are non-ignorable in the real world, have not been considered in this paper. In addition, another weakness (risk cost) has been exposed in the numerical implementation. Hence, solving these disadvantages would be the next step for further research.

马卫民, 林南南, 陈晓轩, 张文芬

\section{基于鲁棒优化的手机公交实时信息优化方法}

\section{摘要}

近几年大量手机实时公交应用涌入市场，公交乘客可 提前查询出行路线以及所乘车辆的到站时间。已有研究表 明, 精确的公交实时信息可以降低乘客候车时的焦虑感, 以及乘客的候车时间。不精确或者错误的公交实时信息不 仅会误导乘客出行, 还会增加乘客对公交的不良印象。另 外, 已有关于公交实时信息优化的研究多是侧重公交实时 到站时间或者公交运行时间预测, 尚未从完善信息内容的 角度考虑优化公交实时信息。基于此, 论文提出了一种鲁
棒优化的方法, 针对单条公交线路的实时到站信息进行优 化。通过鲁棒线性优化, 考虑公交客流的不确定性, 如突 发客流等, 在现有的公交实时到站时间预测中增加运行延 误信息, 以最大节省乘客的出行时间成本为目标, 建立公 交到站时间预测优化模型, 使实时公交APP提供的公交实 时信息更加完善。最后分别运用上海一条市域公交和一条 市内公交的运行信息对模型进行验证。验证结果证明了模 型的有效性以及模型存在的不足。

\section{关键词}

公共交通; 手机App; 实时信息; 鲁棒优化

\section{REFERENCES}

[1] Dziekan K, Kottenhoff K. Dynamic at-stop real-time information displays for public transport: Effects on customers. Transportation Research Part A: Policy and Practice. 2007;41(6): 489-501.

[2] Watkins KE, Ferris B, et al. Where Is My Bus? Impact of mobile real-time information on the perceived and actual wait time of transit riders. Transportation Research Part A: Policy and Practice. 2011;45(8): 839-848.

[3] Grotenhuis JW, Wiegmans BW, Rietveld P. The desired quality of integrated multimodal travel information in public transport: Customer needs for time and effort savings. Transport Policy. 2007;14(1): 27-38.

[4] Casey RF. Automatic Vehicle Location successful transit applications: A cross-cutting study: Improving service and safety. U.S. Joint Program Office for Intelligent Transportation Systems; 2000.

[5] Parker DJ. AVL systems for bus transit: Update. Transportation Research Board; 2008.

[6] Chien SIJ, Ding Y, Wei C. Dynamic bus arrival time prediction with artificial neural networks. Journal of Transportation Engineering. 2002;128(5): 429-438.

[7] Cathey FW, Dailey DJ. A prescription for transit arrival/ departure prediction using automatic vehicle location data. Transportation Research Part C: Emerging Technologies. 2003;11(3-4): 241-264.

[8] Van Hinsbergen CPIJ, van Lint JWC, van Zuylen HJ. Bayesian committee of neural networks to predict travel times with confidence intervals. Transportation Research Part C: Emerging Technologies. 2009;17(5): 498-509.

[9] Liu J, Yu X, Xu Z, et al. A cloud-based taxi trace mining framework for smart city. Software: Practice and Experience. 2017;47(8): 1081-1094.

[10] Kumar V, Kumar BA, Vanajakshi L, et al. Comparison of model based and machine learning approaches for bus arrival time prediction. Proceedings of the $93^{\text {rd }}$ TRB Annual Meeting, 12 - 16 January 2014, Washington D.C., U.S. Transportation Research Board; 2014. 14p.

[11] Chien SIJ, Kuchipudi CM. Dynamic travel time prediction with real-time and historic data. Journal of transportation engineering. 2003;129(6): 608-616.

[12] Shalaby A, Farhan A. Prediction model of bus arrival and departure times using AVL and APC data. Journal of Public Transportation. 2004;7(1): 41-61.

[13] Chen M, Liu X, Xia J, et al. A dynamic bus-arrival time prediction model based on APC data. Computer-Aided Civil and Infrastructure Engineering. 2004;19(5): 364-376.

[14] Bin Y, Zhongzhen Y, Baozhen Y. Bus arrival time 
prediction using support vector machines. Journal of Intelligent Transportation Systems. 2006;10(4): 151-158.

[15] Yu B, Yang ZZ, Wang J. Bus travel-time prediction based on bus speed. Proceedings of the Institution of Civil Engineers-Transport. 2010;163(1): 3-7.

[16] Yu B, Lam WHK, Tam ML. Bus arrival time prediction at bus stop with multiple routes. Transportation Research Part C: Emerging Technologies. 2011;19(6): 1157-1170.

[17] Yu B, Wu S, Yao B, et al. Dynamic vehicle dispatching at a transfer station in public transportation system. Journal of Transportation Engineering. 2011;138(2): 191-201.

[18] Yang $M$, Chen C, Wang L, et al. Bus arrival time prediction using support vector machine with genetic algorithm. Neural Network World. 2016;26(3): 205-217.

[19] Jeong R, Rilett L. Prediction model of bus arrival time for real-time applications. Transportation Research Record: Journal of the Transportation Research Board. 2005;1927: 195-204.

[20] Sapankevych N I, Sankar R. Time series prediction using support vector machines: A survey. IEEE Computational Intelligence Magazine. 2009;4(2): 24-38.

[21] Kumar BA, Jairam R, Arkatkar SS, et al. Real time bus travel time prediction using k-NN classifier. Transportation Letters. 2017; 1-11.

[22] Zhou Y, Luo Q, Liu J. Glowworm swarm optimization for dispatching system of public transit vehicles. Neural Processing Letters. 2014;40(1): 25-33.

[23] Zhou Y, Yao L, Chen Y, et al. Bus arrival time calculation model based on smart card data. Transportation Research Part C: Emerging Technologies. 2017;74: 81-96.

[24] O'Sullivan A, Pereira FC, Zhao J, et al. Uncertainty in bus arrival time predictions: Treating heteroscedasticity with a metamodel approach. IEEE Transactions on Intelligent Transportation Systems. 2016;17(11): 3286-3296.

[25] Nuzzolo A, Comi A, Rosati L. New methods of trip planning for travelers of advanced public transport. Proceedings of the 2015 IEEE $18^{\text {th }}$ International Conference on Intelligent Transportation Systems. 15 - 18 September 2015, Canary Islands, Spain. IEEE; 2015. p. 13-18.

[26] Berrebi SJ, Watkins KE, Laval JA. A real-time bus dispatching policy to minimize passenger wait on a high frequency route. Transportation Research Part B: Methodological. 2015;81: 377-389.
[27] Ma T, Motta G, Liu K. Delivering real-time information services on public transit: A framework. IEEE Transactions on Intelligent Transportation Systems. 2017;18(10): 2642-2656.

[28] Cats O, Loutos G. Evaluating the added-value of online bus arrival prediction schemes. Transportation Research Part A: Policy and Practice. 2016;86: 35-55.

[29] Hernandez T. Flex scheduling for bus arrival time prediction. Transportation Research Record: Journal of the Transportation Research Board. 2014;2418: 110-115.

[30] Balasubramanian P, Rao KR. An adaptive long-term bus arrival time prediction model with cyclic variations. Journal of Public Transportation. 2015;18(1): 1-18.

[31] Zhang F, Shen Q, Clifton K. Examination of traveler responses to real-time information about bus arrivals using panel data. Transportation Research Record: Journal of the Transportation Research Board. 2008;2082: 107-115.

[32] Mishalani RG, McCord MM, Wirtz J. Passenger wait time perceptions at bus stops: Empirical results and impact on evaluating real-time bus arrival information. Journal of Public Transportation. 2006;9(2): 89-106.

[33] Labell LN, Schweiger CP, Kihl M. Advanced public transportation systems: the state of the art: update'92. U.S. Dept. of Transportation; 1992.

[34] Cats O, Koutsopoulos H, Burghout W, et al. Effect of real-time transit information on dynamic path choice of passengers. Transportation Research Record: Journal of the Transportation Research Board. 2011;2217: 46-54.

[35] Nökel K, Wekeck S. Boarding and alighting in frequency-based transit assignment. Transportation Research Record: Journal of the Transportation Research Board. 2009;2111: 60-67.

[36] Bertsimas D, Sim M. The price of robustness. Operations Research. 2004;52(1): 35-53.

[37] Ben-Tal A, Nemirovski A. Robust solutions of linear programming problems contaminated with uncertain data. Mathematical programming. 2000;88(3): 411-424.

[38] Linhares A. Preying on optima: A predatory search strategy for combinatorial problems. Proceedings of the 1998 IEEE International Conference on Systems, Man, and Cybernetics, 11 - 14 October 1998, California, U.S. IEEE; 1998. p. 2974-2978.

[39] Chen M, Liu X, Xia J. Dynamic prediction method with schedule recovery impact for bus arrival time. Transportation Research Record: Journal of the Transportation Research Board. 2005;(1923): 208-217. 